\title{
Spectrofluorimetric determination of gemifloxacin mesylate and linezolid in pharmaceutical formulations: Application of quinone-based fluorophores and enhanced native fluorescence
}

\author{
BAHIA ABBAS MOUSSA ${ }^{1}$ \\ MARIANNE ALPHONSE MAHROUSE ${ }^{1 *}$ \\ MAHMOUD ALI HASSAN ${ }^{2}$ \\ MICHAEL GAMAL FAWZY² \\ 1 Pharmaceutical Chemistry Department \\ Faculty of Pharmacy, Cairo University \\ Kasr El-Aini St., Cairo 11562, Egypt \\ 2 Pharmaceutical Medicinal Chemistry \\ Department, Faculty of Pharmacy \\ Egyptian Russian University, Badr City \\ Cairo, 11829, Egypt
}

Accepted October 20, 2013

\begin{abstract}
Quinone-based fluorophores and enhanced native fluorescence techniques were applied for a fast quantitative analysis of gemifloxacin mesylate (GEM) and linezolid (LIN) in pharmaceutical formulations. For this purpose, three sensitive, accurate and precise spectrofluorimetric methods were developed. GEM, as an n-electron donor, reacts with 7,7,8,8-tetracyanoquinodimethane (method A) and 2,5-dichloro-3,6-dihydroxy-p-benzoquinone (method B) as $\pi$-electron acceptors, forming charge transfer complexes that exhibit high fluorescence intensity at 441 and $390 \mathrm{~nm}$ upon excitation at 260 and $339 \mathrm{~nm}$, respectively. Method C depends on measurement of enhanced native fluorescence of LIN in phosphate buffer ( $\mathrm{pH} 5)$ at $380 \mathrm{~nm}$ upon excitation at $260 \mathrm{~nm}$. Experimental factors affecting fluorescence intensity were optimized. Linearity was obtained over concentration ranges 50-500, 10-60 and $20-400 \mathrm{ng} \mathrm{mL}^{-1}$ for methods A, B and C, respectively. The developed methods were validated and successfully applied for determination of the cited drugs in tablets.

Keywords: gemifloxacin mesylate, linezolid, 7,7,8,8-tetracyanoquinodimethane, 2,5-dichloro-3,6-dihydroxy- $p$-ben-zoquinone, fluorimetry, charge transfer complex
\end{abstract}

Gemifloxacin mesylate (GEM) is a broad-spectrum fluoroquinolone antibacterial agent. Its bactericidal activity depends on inhibition of DNA synthesis. This mode of action involves dual targeting of two bacterial enzymes: DNA gyrase and topoisomerase IV, which are essential for bacterial DNA replication and transcription (1). Chemically, it is designated as ( \pm )-7-[3-(aminomethyl)-4-(methoxyimino)-1-pyrrolidinyl]-1-cyclopropyl-6-fluoro-1,4-dihydro-4-oxo-1,8-naphthyridine-3-carboxylic acid methanesulfonate $(1,2)$ (Fig. 1a).

\footnotetext{
* Correspondence; e-mail: mariannealphonse@yahoo.com
} 
a)

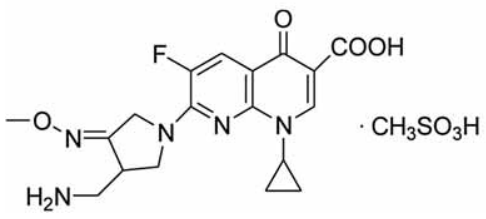

b)

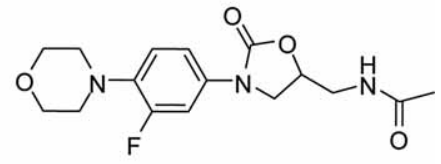

Fig. 1. Chemical structures of: a) gemifloxacin mesylate and b) linezolid.

GEM is not official in any pharmacopoeia. The literature survey revealed several reported analytical approaches for its determination in pharmaceutical dosage forms and in biological fluids. Various spectrophotometric (3-11) and spectrofluorimetric $(12,13)$ methods were described. Chromatographic methods were also reported and include capillary electrophoresis (14), HPTLC (15) and HPLC (16).

Linezolid [LIN, Fig. 1b, (S)-N-(\{3-[3-fluoro-4-(morpholin-4-yl)phenyl]-2-oxo-1,3-oxazolidin-5-yl ; methyl) acetamide], belongs to a new class of antibacterial agents, the oxazolidinones. It exhibits a unique mechanism of action based on inhibition of bacterial protein synthesis. Clinical utility appears in the treatment of serious infections caused by multi-resistant Gram positive bacteria (17).

Only few methods were reported for the determination of LIN in tablets, including spetrophotometric (18), TLC (19) and HPLC (20) methods, either alone or in the presence of alkaline induced degradation products. Estimation of LIN in biological fluids using LC/MS (21) and HPLC (22) was also described.

The widespread use of these antibacterial drugs and the need for clinical and pharmacological studies require fast and sensitive analytical methods for their determination in pharmaceutical formulations. Chromatography, the most common technique applied, generally requires sophisticated instruments and high analysis cost which limit its routine use in analytical laboratories. Therefore, development of alternative methods is desirable. Fluorescence spectroscopy is considered as one of convenient analytical techniques because it possesses good analytical selectivity, improved limit of detection when compared to spectrophotometric methods and wide availability in most laboratories. Therefore, the purpose of the present investigation was to develop sensitive, accurate and precise methods for the determination of GEM and LIN using spectrofluorimetry.

\section{EXPERIMENTAL}

\section{Chemicals and reagents}

Pure samples of GEM and LIN were kindly provided by El Obour Modern Pharmaceutical Industries Company (Egypt) and their certified purity was 99.8 and $99 \%$, respectively. 7,7,8,8-Tetracyanoquinodimethane (TCNQ) and 2,5-dichloro-3,6-dihydroxy- $p$ -benzoquinone ( $p$-chloranilic acid, CLA) were purchased from Sigma-Aldrich Chemie $\mathrm{GmbH}$ (Germany) and were freshly prepared as $2.4 \times 10^{-3} \mathrm{~mol} \mathrm{~L}^{-1}$ solutions in acetonitrile. Methanol (HPLC grade, Labscan, Poland) and acetonitrile (HPLC grade, Riedel 
B. A. Moussa et al.: Spectrofluorimetric determination of gemifloxacin mesylate and linezolid in pharmaceutical formulations: Application of quinone-based fluorophores and enhanced native fluorescence, Acta Pharm. 64 (2014) 15-28.

de Haën, Germany) were used. Disodium hydrogen phosphate was supplied by EL-Nasr Pharmaceutical Chemicals Co., Egypt. Phosphate buffer was composed of $0.1 \mathrm{~mol} \mathrm{~L}^{-1}$ disodium hydrogen phosphate (EL-Nasr Pharmaceutical Chemicals) in water and adjusted to pH 5 with orthophosphoric acid (Riedel de Haën).

\section{Pharmaceutical formulations}

Two pharmaceutical dosage forms were obtained from the local market in Egypt: Factive ${ }^{\circledR}$ tablets (Hikma Pharma, Egypt), labeled to contain GEM mesylate equivalent to 320 mg GEM base per one tablet, and Averzolid ${ }^{\circledR}$ tablets (El Obour Modern Pharmaceutical Industries Company, Cairo, Egypt), labeled to contain 600 mg LIN.

\section{Equipment}

Fluorescence spectra were recorded and intensity measurements were made on an RF-1501 spectrofluorimeter (Shimadzu, Japan). A pH meter model 3505 (Jenway, UK) was used for all $\mathrm{pH}$ measurements.

\section{Standard solutions}

Standard stock solutions of $100 \mu \mathrm{g} \mathrm{mL}^{-1}$ of GEM and LIN were prepared in acetonitrile and in methanol, respectively. Working solutions of GEM, having concentrations of $1 \mu \mathrm{g} \mathrm{mL} \mathrm{m}^{-1}$ and $0.5 \mu \mathrm{g} \mathrm{mL}-1$, were prepared from its stock solution by dilution using acetonitrile, for methods A and B, respectively. For method C, further dilution of LIN stock solution was carried out to obtain a working solution of $1 \mu \mathrm{g} \mathrm{mL}-1$ in methanol.

\section{General procedures}

Method A (TCNQ method). - Aliquots containing (500-5000 ng) GEM were transferred into a series of $10-\mathrm{mL}$ volumetric flasks. An accurate aliquot of TCNQ solution $(2.4 \times$ $10^{-6} \mathrm{~mol} \mathrm{~L}^{-1}$ ) was added, the reaction mixture was mixed and allowed to stand for 40 min. The volume was completed to $10 \mathrm{~mL}$ with acetonitrile. After standing for $15 \mathrm{~min}$, fluorescence intensity was measured at the emission wavelength $\left(\lambda_{\mathrm{em}}\right)$ of $441 \mathrm{~nm}$ upon excitation at $260 \mathrm{~nm}$, against a similarly treated blank. A linear calibration curve was obtained by plotting the fluorescence intensity against the corresponding concentration of the drug and the regression equation was computed.

Method B (CLA method). - Into a series of 10-mL volumetric flasks, accurately measured aliquots of the GEM working standard solution equivalent to 100-600 ng were transferred and an accurate aliquot of CLA solution $\left(1.1 \times 10^{-6} \mathrm{~mol} \mathrm{~L}^{-1}\right)$ was added. The reaction was left for completion for $5 \mathrm{~min}$ before dilution to volume with acetonitrile. After standing for $5 \mathrm{~min}$, fluorescence intensity was measured at $\lambda_{\mathrm{em}} 390 \mathrm{~nm}$ using the excitation wavelength $\left(\lambda_{\mathrm{ex}}\right)$ of $339 \mathrm{~nm}$, against a similarly treated blank. The calibration graph was constructed and the regression equation was computed.

Method C (native fluorescence method). - Varying aliquots of the LIN working standard solution equivalent to 200-4000 ng were accurately measured and transferred into a series of $10-\mathrm{mL}$ volumetric flasks. An accurate aliquot of phosphate buffer $\left(5 \times 10^{-4}\right.$ 
B. A. Moussa et al.: Spectrofluorimetric determination of gemifloxacin mesylate and linezolid in pharmaceutical formulations: Application of quinone-based fluorophores and enhanced native fluorescence, Acta Pharm. 64 (2014) 15-28.

mol L $\mathrm{L}^{-1}, \mathrm{pH} 5$ ) was added, the volume was adjusted to the mark with water and mixed well. Fluorescence intensity was measured at $\lambda_{\text {em }}$ at $380 \mathrm{~nm}\left(\lambda_{\text {ex }} 260 \mathrm{~nm}\right)$ against a blank similarly prepared without adding LIN. The calibration graph was constructed and the regression equation was computed.

\section{Analysis of pharmaceutical formulations}

Ten tablets of each formulation were accurately weighed and finely powdered. A quantity of the mixed powder equivalent to $10 \mathrm{mg}$ of the active component was transferred into a 100-mL volumetric flask, dissolved either in $25 \mathrm{~mL}$ acetonitrile (methods A and B) or methanol (method C), stirred for $30 \mathrm{~min}$ and then completed to volume with the same solvent. The contents were mixed well and filtered and the first portion of the filtrate was rejected. The filtrate was further diluted quantitatively to obtain suitable concentrations for the analysis by the proposed methods, as described under the general procedures section. The contents of the tablets were calculated using the corresponding regression equations.

\section{Stoichiometry of the reaction}

The reaction stoichiometry between GEM and quinone-based reagents (TCNQ and CLA) was investigated by the limiting logarithmic method (23). Two sets of solutions were prepared, the first set had a fixed concentration of GEM and varying concentrations of the reagent while the second one had a fixed concentration of the reagent and varying concentrations of the drug. Logarithms of the obtained fluorescence intensities for the reaction of GEM and each reagent were plotted as a function of the logarithms of the concentrations of the reagent and GEM in the first and second sets of solutions. The slopes of straight lines were computed and the ratios between slopes were calculated.

\section{Methods validation}

The developed methods were validated pursuant to the guidelines of the International Conference on Harmonisation (ICH) for validation of analytical procedures (24).

Linearity and range. - Linearity of the methods was evaluated by linear regression analysis, which was calculated by the least square method. Six different concentrations of standard solutions of each of GEM and LIN were analyzed by the developed methods. All measurements were carried out in triplicate. The assays were performed according to the general procedures previously established for the proposed methods. Three calibration curves were obtained by plotting fluorescence intensities vs. concentrations of the drugs and regression equations were computed.

Accuracy. - Accuracy of the proposed methods was tested by analyzing different concentrations of GEM and LIN solutions (in triplicate for each concentration). The accuracy was determined in terms of percentage recovery. In addition, the validity of the suggested methods was checked by applying the standard addition technique, in which the recoveries of known amounts of GEM and LIN, added to their sample solutions of known concentrations, were calculated. 
B. A. Moussa et al.: Spectrofluorimetric determination of gemifloxacin mesylate and linezolid in pharmaceutical formulations: Application of quinone-based fluorophores and enhanced native fluorescence, Acta Pharm. 64 (2014) 15-28.

Precision. - Method precision was estimated by measuring repeatability (intra-day precision) and intermediate precision (inter-day precision). Intra-day precision was assessed by preparing samples of drug standard solutions at varying concentration levels, covering low, medium and high concentrations of the linearity range and analyzing them in triplicate on the same day using the proposed methods. Inter-day precision was determined by analyzing the same samples on three consecutive days. The precision of the method was expressed as relative standard deviation.

Selectivity. - Selectivity is the ability of the analytical method to measure analyte response in the presence of foreign substances. In the present work, selectivity was ascertained by applying the developed methods to pharmaceutical dosage forms and the resulting emission spectra were checked for the appearance of any new spectra of excipients.

Limit of detection and limit of quantification. - The limit of detection (LOD) and limit of quantification $(L O Q)$ were determined based on the standard deviation of the intercept of the calibration line (SD) and the slope of regression lines, using the formula: $3.3 \times \mathrm{SD} /$ slope and $10 \times \mathrm{SD} /$ slope, respectively.

\section{RESULTS AND DISCUSSION}

Sensitive methods for the determination of GEM and LIN using spectrofluorimetry were developed. Two of the proposed methods were based on the formation of fluorescent charge transfer complexes, whilw the third was performed by enhancing the native fluorescence of the drug using phosphate buffer ( $\mathrm{pH}$ 5).

\section{Method A (TCNQ method) and method B (CLA method)}

Excitation and emission spectra. - The reaction of amines as n-electron donors with quinone-based reagents such as 7,7,8,8-tetracyanoquinodimethane (TCNQ) and 2,5-dichloro-3,6-dihydroxy- $p$-benzoquinone (CLA) as $\pi$-electron acceptors leads to the formation of charge transfer complexes which have been shown to exhibit sensitive fluorescence $(25,26)$. Charge transfer spectrofluorimetry is associated with major advantages such as good selectivity, low detection limit and hence high sensitivity. Since GEM structure contains a basic centre, tertiary nitrogen of the pyrrolidine ring, TCNQ and CLA were selected as valuable derivatizing agents to form quinone-based fluorophores. For this reason, the present study was devoted to investigate the reaction between GEM and quinone-based reagents and employ this reaction in the development of two new, simple and sensitive spectrofluorimetric methods for the determination of GEM in tablets. The reaction was performed under optimal experimental parameters and the fluorescence excitation and emission spectra of the charge transfer complexes produced were recorded (Fig. 2).

Optimization of experimental parameters. - Different experimental parameters affecting the fluorescence development of the reaction product and its stability were studied and optimized. Such factors were investigated by varying the parameters, one at a time, keeping the others fixed and observing the effect produced on the fluorescence intensity. 
B. A. Moussa et al.: Spectrofluorimetric determination of gemifloxacin mesylate and linezolid in pharmaceutical formulations: Application of quinone-based fluorophores and enhanced native fluorescence, Acta Pharm. 64 (2014) 15-28.

Fig. 2. Fluorescence excitation and emission spectra of the charge transfer complex of: a) GEM (500 ng $\left.\mathrm{mL}^{-1}\right)$ with TCNQ (-) and blank (-----), and b) GEM (60 ng $\mathrm{mL}^{-1}$ ) with CLA and blank (-----).
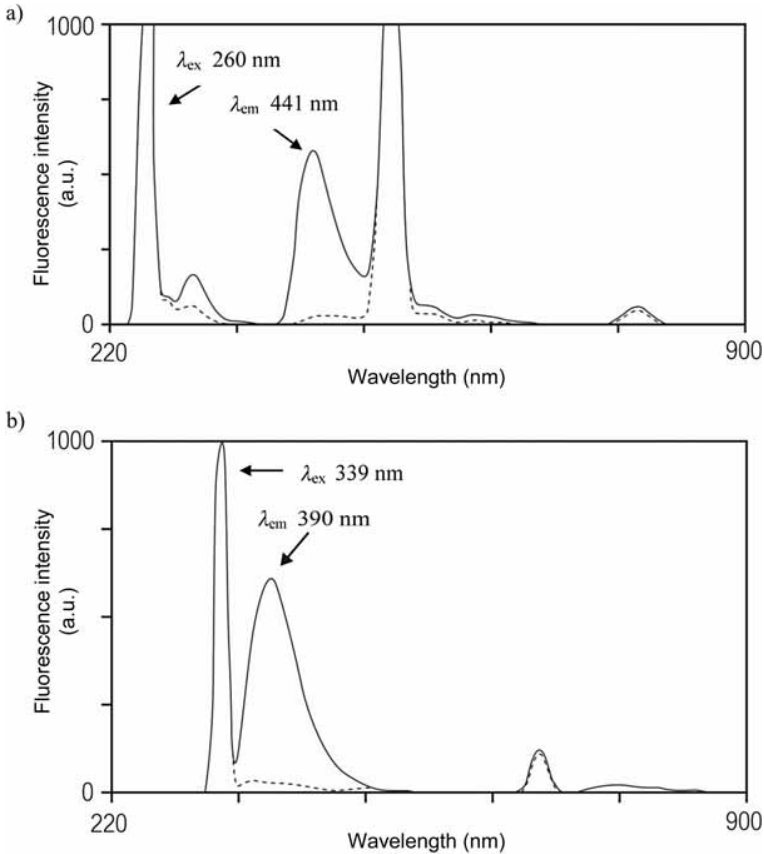

The influence of TCNQ and CLA molar concentration was studied. It was found that final molar concentrations of TCNQ and CLA sufficient for the production of maximum and reproducible fluorescence intensity were $2.4 \times 10^{-6}$ and $1.1 \times 10^{-6} \mathrm{~mol} \mathrm{~L}^{-1}$, respectively.

Fluorescence spectral characteristics of the charge transfer complex formed in different diluting solvents were compared. The studied solvents involved water, methanol, ethanol, acetonitrile and acetone. Experimental results indicated that acetonitrile afforded the maximum and stable fluorescence emission for both methods (Table I).

Different reaction time intervals (10-45, 2.5-20 min, for methods A and B, respectively) were tested to ascertain the time after which the reaction product attains its highest fluorescence intensity. It was found that the reaction product reached the highest fluorescence within 40 and $5 \mathrm{~min}$, for methods A and B, respectively.

To establish the optimum reaction temperature, GEM (500 and $60 \mathrm{ng} \mathrm{mL}^{-1}$ ) was allowed to react with TCNQ $\left(2.4 \times 10^{-6} \mathrm{~mol} \mathrm{~L}^{-1}\right)$ and CLA $\left(1.1 \times 10^{-6} \mathrm{~mol} \mathrm{~L}^{-1}\right)$, respectively, at different temperatures. Maximum fluorescence intensity was obtained at room temperature $\left(25^{\circ} \mathrm{C}\right)$. Increasing the reaction temperature above room temperature would result in a subsequent decrease in fluorescence intensity of the reaction product (Table I).

Stability of the fluorescent product. - Stability of the formed product was checked by applying the chosen optimum conditions and measuring the fluorescence intensity of the reaction solution (after dilution) at different time intervals. Fluorescence intensity was found to increase and reach a stable value from 15 to $50 \mathrm{~min}$ and 5 to $60 \mathrm{~min}$, for me- 
B. A. Moussa et al.: Spectrofluorimetric determination of gemifloxacin mesylate and linezolid in pharmaceutical formulations: Application of quinone-based fluorophores and enhanced native fluorescence, Acta Pharm. 64 (2014) 15-28.

Table I. Effects of diluting solvent and temperature on the reactions of GEM with TCNQ and CLA and effects of buffer $\mathrm{pH}$ and concentration on the enhancement of native fluorescence intensity of LIN

\begin{tabular}{|c|c|c|c|c|c|c|c|c|c|}
\hline GEM & & & & & LIN & & & & \\
\hline \multirow{2}{*}{ Solvent } & \multicolumn{2}{|c|}{$\begin{array}{l}\text { Relative fluorescence } \\
\text { intensity }^{\mathrm{a}}\end{array}$} & \multirow{2}{*}{ 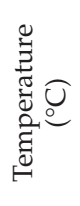 } & \multicolumn{2}{|c|}{$\begin{array}{l}\text { Relative fluorescence } \\
\text { intensity }^{\mathrm{a}} \\
\text { (in acetonitrile) }\end{array}$} & \multirow{2}{*}{ 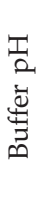 } & \multirow{2}{*}{ 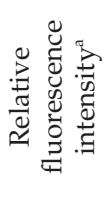 } & \multirow{2}{*}{ 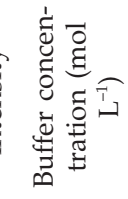 } & \multirow{2}{*}{ 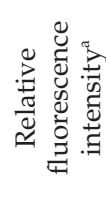 } \\
\hline & $\begin{array}{l}\text { TCNQ } \\
\text { method }\end{array}$ & $\begin{array}{l}\text { CLA } \\
\text { method }\end{array}$ & & $\begin{array}{l}\text { TCNQ } \\
\text { method }\end{array}$ & $\begin{array}{l}\text { CLA } \\
\text { method }\end{array}$ & & & & \\
\hline Acetone & 1 & 7 & 25 & 3 & 1.5 & 1 & 1 & $2 \times 10^{-4}$ & 1 \\
\hline Acetonitrile & 123 & 10 & 40 & 2.5 & 1 & 3 & 2 & $3 \times 10^{-4}$ & 1 \\
\hline Ethanol & 63 & 2 & 60 & 1 & 1 & 5 & 3 & $4 \times 10^{-4}$ & 1.5 \\
\hline Methanol & 46 & 1 & 80 & 1 & 1 & 7 & 1 & $4.5 \times 10^{-4}$ & 2 \\
\hline \multirow[t]{2}{*}{ Isopropanol } & 33 & 2 & & & & & & $5 \times 10^{-4}$ & 3 \\
\hline & & & & & & & & $6 \times 10^{-4}$ & 2 \\
\hline
\end{tabular}

a Relative fluorescence intensity is the ratio relative to the lowest intensity, in the respective column.

a)
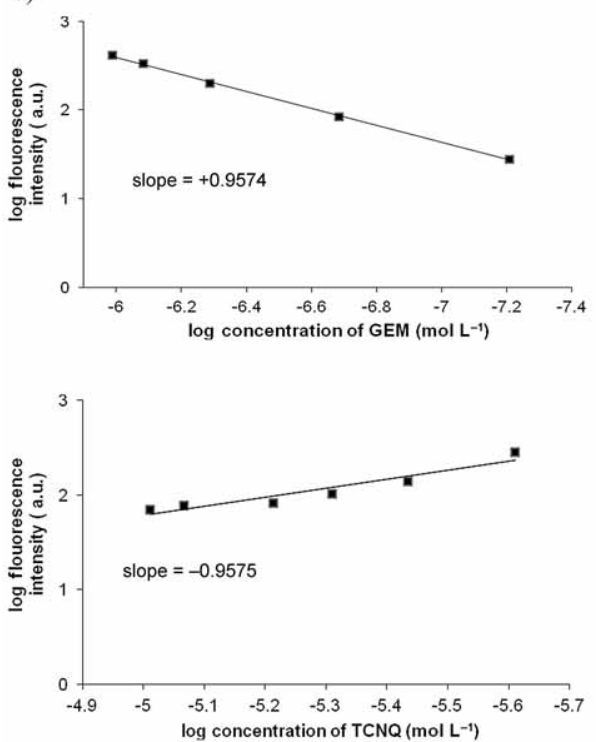

b)
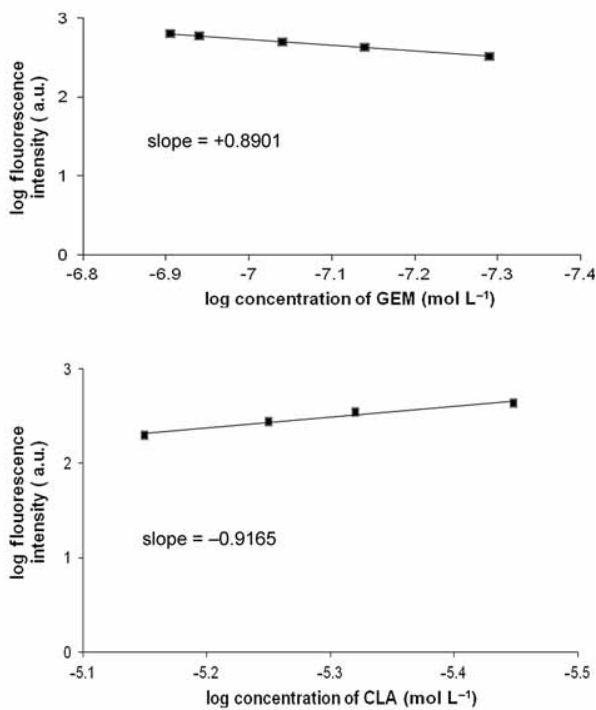

Fig. 3. Determination of the stoichiometry of the reaction of GEM with: a) TCNQ and b) CLA, by the limiting logarithmic method.

thods A and B, respectively. Therefore, measurements were carried out after standing for 15 and 5 min, for methods A and B, respectively. Stability of the fluorescent products up to an hour allows the analysis of a large number of samples in quality control laboratories. 
B. A. Moussa et al.: Spectrofluorimetric determination of gemifloxacin mesylate and linezolid in pharmaceutical formulations: Application of quinone-based fluorophores and enhanced native fluorescence, Acta Pharm. 64 (2014) 15-28.

Stoichiometry and mechanisms of reactions. - Molar ratio of the reactants (drug/reagent) in the charge transfer complex was determined by the limiting logarithmic method (23). Two straight lines were obtained by plotting log fluorescence intensity vs. $\log$ molar concentration of the drug in one plot and log fluorescence intensity vs. log molar concentration of the reagent in another one (Figs. 3a and $3 b$ ). The values of slopes were $0.9574,-0.9575$ and $0.8901,-0.9165$ for methods A and B, respectively, confirming the $1: 1$ molar ratio of the reactants for both methods. This finding was anticipated by the presence of an electron donating centre, tertiary nitrogen of pyrrolidine ring in GEM molecule, which interacts with TCNQ and CLA (strong $\pi$-electron acceptors) forming charge transfer complexes of $n-\pi$ type (Fig. 4).

\section{Method C (enhanced native fluorescence)}

Excitation and emission spectra. - LIN was found to emit weak fluorescence in aqueous solution and in methanol. However, this weak native fluorescence was enhanced in phosphate buffer ( $\mathrm{pH}$ 5). This fact has been used to develop an improved spectrofluorimetric method for the determination of LIN in tablets. Fig. 6 shows the fluorescence

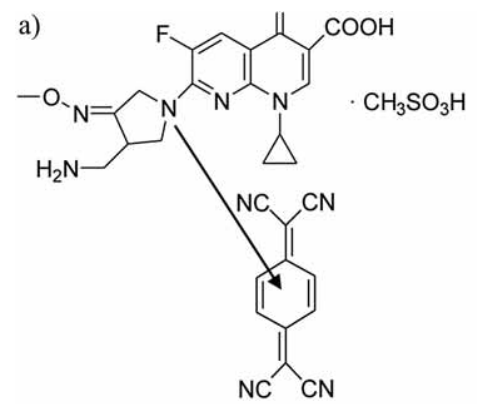

GEM/TCNQ charge transfer complex<smiles>CO/N=C1\CN(c2nc3c(cc2F)c(=O)c(C(=O)O)cn3C2CC2)CC1CN</smiles>

GEM/CLA charge transfer complex

Fig. 4. The suggested structures of: a) GEM/TCNQ and b) GEM/CLA charge transfer complexes.

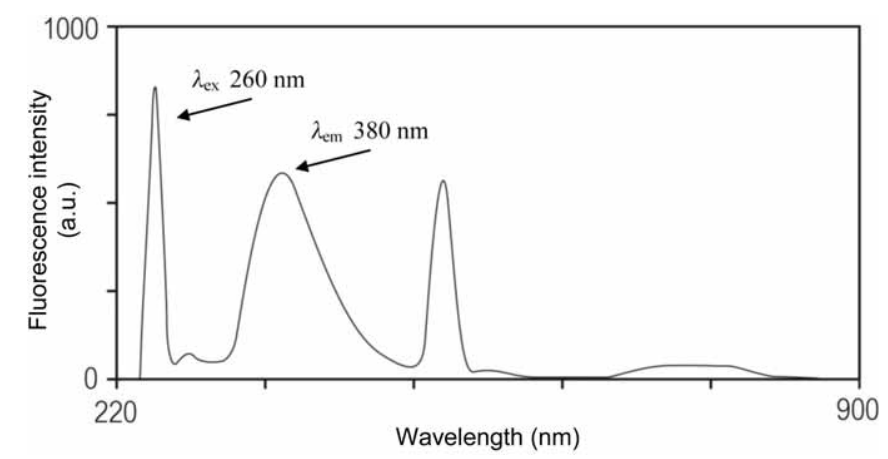

Fig. 5. Fluorescence excitation and emission spectra of LIN (350 ng mL-1) in water. 
B. A. Moussa et al.: Spectrofluorimetric determination of gemifloxacin mesylate and linezolid in pharmaceutical formulations: Application of quinone-based fluorophores and enhanced native fluorescence, Acta Pharm. 64 (2014) 15-28.

spectrum of LIN having an excitation maximum at $260 \mathrm{~nm}$ and an emission maximum at $380 \mathrm{~nm}$. Various experimental factors that affect the enhancement of fluorescence intensity were investigated.

Optimization of experimental parameters. - The influence of $\mathrm{pH}$ on the native fluorescence of LIN was investigated by measuring the fluorescence intensity of the drug using buffer solutions of varying $\mathrm{pH}$ values. Maximum fluorescence intensity was obtained upon using phosphate buffer of $\mathrm{pH} 5$. The increase in fluorescence intensity was tested by adding different molar concentrations of the buffer $\left(2 \times 10^{-4}-6 \times 10^{-4} \mathrm{~mol} \mathrm{~L}^{-1}\right)$. It was observed that $5 \times 10^{-4} \mathrm{~mol} \mathrm{~L}^{-1}$ phosphate buffer ( $\left.\mathrm{pH} 5\right)$ showed the highest fluorescence intensity (Table I).

Upon diluting the solution of the drug in phosphate buffer ( $\mathrm{pH}$ 5) with different solvents, water was found to be the most suitable solvent. This was attributed to the lowest background noise and satisfactory results obtained over the linearity range of 20-400 ng mL-1.

\section{Methods validation}

Linearity and range. - Under the optimum experimental conditions, linear correlations were established over the concentrations ranges of 50-500, 10-60 and 20-400 ng mL-1,

Table II. Assay parameters for the determinations of GEM and LIN

\begin{tabular}{|c|c|c|c|}
\hline \multirow[b]{2}{*}{ Parameter } & \multicolumn{2}{|c|}{ GEM } & \multirow{2}{*}{$\begin{array}{l}\text { LIN } \\
\text { Native fluorescence } \\
\text { method (method C) }\end{array}$} \\
\hline & $\begin{array}{l}\text { TCNQ method } \\
(\text { method } A)\end{array}$ & $\begin{array}{l}\text { CLA method } \\
\text { (method B) }\end{array}$ & \\
\hline Excitation wavelength (nm) & 260 & 339 & 260 \\
\hline Emission wavelength (nm) & 441 & 390 & 380 \\
\hline$L O D\left(\text { ng } \mathrm{mL}^{-1}\right)^{\mathrm{a}}$ & 7.38 & 0.86 & 4.28 \\
\hline$L O Q\left(\text { ng mL }{ }^{-1}\right)^{\mathrm{a}}$ & 22.37 & 2.60 & 12.95 \\
\hline Range of linearity (ng mL ${ }^{-1}$ ) & $50-500$ & $10-60$ & $20-400$ \\
\hline Correlation coefficient $(R)$ & 0.9998 & 0.9998 & 0.9998 \\
\hline $\mathrm{SD}_{\mathrm{b}}(\%)$ & 0.01 & 0.07 & 0.01 \\
\hline $\mathrm{SD}_{\mathrm{a}}(\%)$ & 1.81 & 2.76 & 1.0 \\
\hline Confidence limits of the slope & $0.8079 \pm 0.0167$ & $10.6201 \pm 0.1971$ & $0.8937 \pm 0.0167$ \\
\hline Confidence limits of the intercept & $3.0371 \pm 5.0162$ & $51.2392 \pm 7.6645$ & $130.3979 \pm 3.6282$ \\
\hline Repeatability (RSD, \%) ${ }^{\mathrm{c}}$ & $1.063,1.056,0.916$ & $1.358,0.321,0.473$ & $1.000,0.425,0.712$ \\
\hline Intermediate precision $(\mathrm{RSD}, \%)^{\mathrm{d}}$ & $0.280,0.739,0.608$ & $0.195,0.089,0.338$ & $1.004,0.561,0.454$ \\
\hline \multicolumn{4}{|c|}{$\begin{array}{l}\text { a Limits of detection and quantification are determined via calculations }(24): L O D=3.3 \times \mathrm{SD} / \text { slope; } L O Q= \\
10 \times \mathrm{SD} / \text { slope; } \mathrm{SD} \text { is standard deviation of the intercept of regression line. }\end{array}$} \\
\hline \multicolumn{4}{|c|}{$\mathrm{b} \mathrm{SD}_{\mathrm{b}}$ and $\mathrm{SD}_{\mathrm{a}}$ are $\mathrm{SD}_{\mathrm{s}}$ of calibration line slope and intercept, resp. } \\
\hline \multicolumn{4}{|c|}{$\begin{array}{l}\text { c The intra-day precision, average of three concentrations of GEM }\left(150,250 \text { and } 350 \mathrm{ng} \mathrm{mL}^{-1} \text {, in case of TCNQ }\right. \\
\text { method; } 25,35 \text { and } 55 \mathrm{ng} \mathrm{mL}-1 \text {, in case of CLA method) and of LIN }\left(90,230 \text { and } 350 \mathrm{ng} \mathrm{mL}^{-1} \text {, in case of }\right. \\
\text { native fluorescence method), repeated three times within a day. }\end{array}$} \\
\hline \multicolumn{4}{|c|}{$\begin{array}{l}\mathrm{d} \text { The inter-day precision, average of three concentrations of GEM }\left(150,250 \text { and } 350 \mathrm{ng} \mathrm{mL}^{-1} \text {, in case of TCNQ }\right. \\
\text { method; } 25,35 \text { and } 55 \mathrm{ng} \mathrm{mL}-1 \text {, in case of CLA method) and of LIN }\left(90,230 \text { and } 350 \mathrm{ng} \mathrm{mL}^{-1} \text {, in case of }\right. \\
\text { native fluorescence method), repeated three times on three successive days. }\end{array}$} \\
\hline
\end{tabular}


B. A. Moussa et al.: Spectrofluorimetric determination of gemifloxacin mesylate and linezolid in pharmaceutical formulations: Application of quinone-based fluorophores and enhanced native fluorescence, Acta Pharm. 64 (2014) 15-28.

for methods A, B and C, respectively. The high values of correlation coefficients $>0.9998$ for all the proposed methods indicate excellent correlation between fluorescence intensities and analyte concentrations. The analytical data of the calibration curves including standard deviations of the slope and intercept are summarized in Table II.

Accuracy. - The results of accuracy are revealed in Table III. Good recoveries were obtained, confirming that the developed methods are accurate. In addition, the proposed methods were applied successfully to the determination of GEM and LIN in pharmaceutical dosage forms. By applying the standard addition technique, the mean percentage recoveries of the added standard ranged from 99.6 to $100.7 \%$, indicating good accuracy of the method. The results of analysis of the pharmaceutical dosage forms and the recovery study are shown in Tables IV and V.

Precision. - RSD values were found to be up to $1.4 \%$ in case of repeatability and up to $1.0 \%$ in the case of intermediate precision, for methods A, B and C, as reported in Table II. Values of the percentage relative standard deviation did not exceed $2 \%$, proving good precision of the suggested methods.

Selectivity. - No interference from any of the excipients was found at the excitation/ emission wavelengths of the examined drugs. In addition, the spectrum of each drug in the tablet solution is identical to the spectrum received by the standard solution at the wavelengths applied. Besides, results of the analysis of pharmaceutical dosage forms, as revealed in Tables IV and V, show good recoveries (ranging between 98.5-101.5 \%). Therefore, the proposed methods are highly selective for the determination of GEM and LIN, with no interference from the frequently encountered excipients in pharmaceutical formulations.

Limit of detection and limit of quantification. - LOD and LOQ values, as summarized in Table I, reveal that the proposed methods have adequate sensitivity, which is higher than that in the reported spectrophotometric methods with LODs ranging 21-124 $\mathrm{ng} \mathrm{mL}-1$.

Table III. Accuracy of the proposed methods for the determination of GEM and LIN in pure samples

\begin{tabular}{|c|c|c|c|c|c|}
\hline \multicolumn{4}{|c|}{ GEM } & \multirow{2}{*}{\multicolumn{2}{|c|}{ 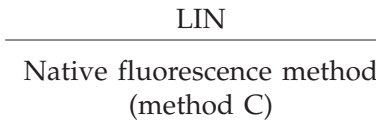 }} \\
\hline \multicolumn{2}{|c|}{ TCNQ method (method A) } & \multicolumn{2}{|c|}{ CLA method (method B) } & & \\
\hline $\begin{array}{l}\text { Claimed taken } \\
\qquad\left(\mathrm{ng} \mathrm{mL}^{-1}\right)\end{array}$ & $\begin{array}{l}\text { Recovery } \\
(\%)^{\mathrm{a}}\end{array}$ & $\begin{array}{l}\text { Claimed taken } \\
\qquad\left(\mathrm{ng} \mathrm{mL}^{-1}\right)\end{array}$ & $\begin{array}{l}\text { Recovery } \\
(\%)^{\mathrm{a}}\end{array}$ & $\begin{array}{l}\text { Claimed taken } \\
\left(\text { ng } \mathrm{mL}^{-1}\right)\end{array}$ & $\begin{array}{l}\text { Recovery } \\
(\%)^{\mathrm{a}}\end{array}$ \\
\hline 90.00 & 101.6 & 15.00 & 100.0 & 90.00 & 100.9 \\
\hline 150.00 & 99.7 & 25.00 & 101.4 & 150.00 & 101.1 \\
\hline 250.00 & 98.2 & 35.00 & 99.6 & 230.00 & 100.8 \\
\hline 350.00 & 100.4 & 45.00 & 101.0 & 250.00 & 99.3 \\
\hline 450.00 & 100.6 & 55.00 & 99.8 & 350.00 & 99.6 \\
\hline Mean $\pm S D$ & $100.1 \pm 1.3$ & & $100.4 \pm 0.8$ & & $100.3 \pm 0.8$ \\
\hline
\end{tabular}

${ }^{\mathrm{a}} n=3$. 
B. A. Moussa et al:: Spectrofluorimetric determination of gemifloxacin mesylate and linezolid in pharmaceutical formulations: Application of quinone-based fluorophores and enhanced native fluorescence, Acta Pharm. 64 (2014) 15-28.

Table V. Determination of LIN in tablets by the proposed method

\begin{tabular}{|c|c|c|c|c|c|}
\hline $\begin{array}{l}\text { Claimed taken } \\
\qquad\left(\mathrm{ng} \mathrm{mL}^{-1}\right)\end{array}$ & $\begin{array}{l}\text { Pure added } \\
\left(\text { ng } \mathrm{mL}^{-1}\right)\end{array}$ & $\begin{array}{l}\text { Conc. found } \\
\text { of tablet } \\
\left(\mathrm{ng} \mathrm{mL} \mathrm{m}^{-1}\right)\end{array}$ & $\begin{array}{l}\text { Conc. found } \\
\text { of total } \\
\left(\text { ng } \mathrm{mL}^{-1}\right)\end{array}$ & $\begin{array}{l}\text { Recovery of } \\
\text { total }(\%)^{\mathrm{a}}\end{array}$ & $\begin{array}{l}\text { Recovery of } \\
\text { added }(\%)^{\mathrm{a}}\end{array}$ \\
\hline \multirow[t]{3}{*}{100.00} & 80.00 & 101.1 & 180.00 & 100.8 & 100.4 \\
\hline & 100.00 & & 200.00 & 100.9 & 100.6 \\
\hline & 120.00 & & 220.00 & 100.1 & 99.2 \\
\hline \multirow[t]{3}{*}{150.00} & 100.00 & 151.4 & 250.00 & 100.6 & 99.9 \\
\hline & 150.00 & & 300.00 & 100.4 & 99.8 \\
\hline & 200.00 & & 197.63 & 99.8 & 99.8 \\
\hline Mean \pm SD & & & & $100.4 \pm 0.4$ & $100.0 \pm 0.5$ \\
\hline
\end{tabular}

a $n=3$

Table VI. Statistical comparison of the results obtained by applying the proposed fluorimetric methods for the determination of GEM and LIN

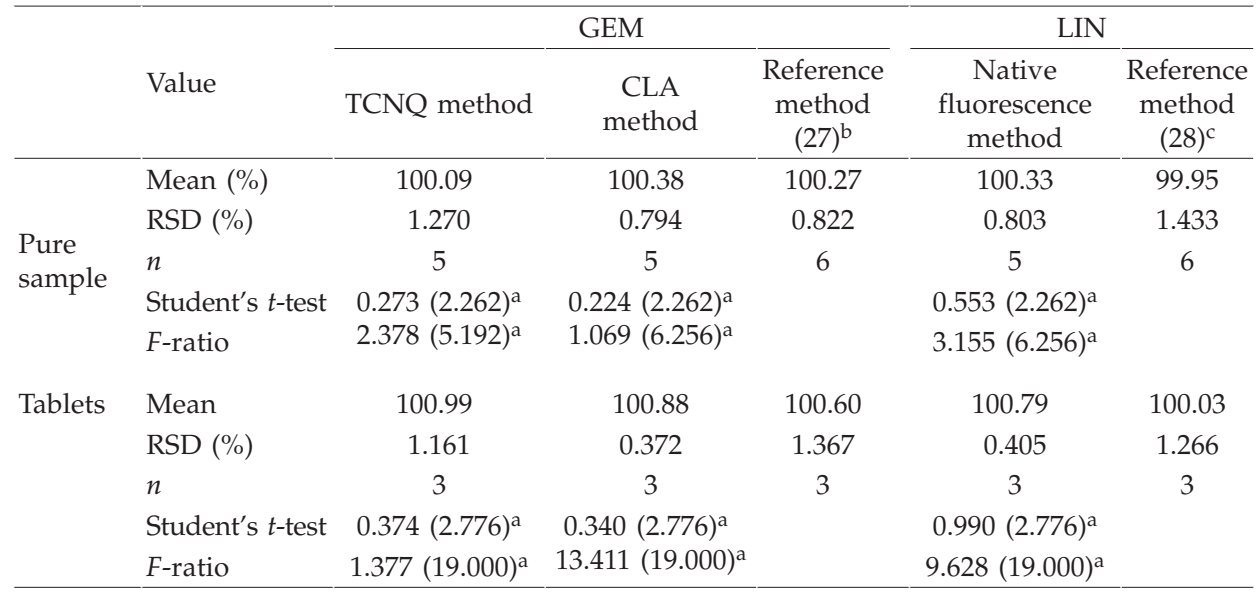

a Values in the parentheses are the corresponding values of $t$ - and $F$ - at $p=0.05$.

${ }^{\mathrm{b}}$ HPLC method (27).

\section{CONCLUSIONS}

The present study describes the utility of quinone-based reagents such as TCNQ and CLA for the development of quinone-based fluorophores. In addition, successful evaluation of native fluorescence as an analytical tool for the analysis of drugs was considered. These concepts were explored for spectrofluorimetric determinations of novel fluoroquinolone and oxazolidinone antibacterial agents, gemifloxacin mesylate and linezolid, 
B. A. Moussa et al.: Spectrofluorimetric determination of gemifloxacin mesylate and linezolid in pharmaceutical formulations: Application of quinone-based fluorophores and enhanced native fluorescence, Acta Pharm. 64 (2014) 15-28.

with high sensitivity and selectivity. Two of the proposed methods were based on the formation of fluorescent charge transfer complexes, while the third was performed by enhancing the native fluorescence of the drug using phosphate buffer ( $\mathrm{pH}$ 5). Optimum experimental parameters affecting the reaction of GEM with TCNQ and CLA and those enhancing the native fluorescence of LIN were investigated. Stoichiometric ratio and mechanisms of reactions of GEM were studied and postulated. The suggested methods have the advantages of simplicity, accuracy and high sensitivity and they allowed successful determination of the cited drugs in tablets. Therefore, the methods are valuable for routine application in quality control laboratories.

\section{REFERENCES}

1. T. L. Lemke, D. A. Williams, V. F. Roche and S. W. Zito, Foye's Principles of Medicinal Chemistry, $6^{\text {th }}$ ed., Wolters Kluwer, Lippincott Williams \& Wilkins, New York 2008.

2. M. J. O'Neil, P. E. Heckelman, C. B. Koch, K. J. Roman, C. M. Kenny and M. R. D'Arecca, The Merck Index, An Encyclopedia of Chemicals, Drugs and Biologicals, $14^{\text {th }}$ ed., Merck Research Laboratories Division of Merck \& Co., Inc., Whitehouse Station (NJ) 2006.

3. B. A. Moussa, M. A. Mahrouse, M. A. Hassan and M. G. Fawzy, Stability indicating spectrophotometric and TLC densitometric methods for the determination of gemifloxacin mesylate in tablet form, Anal. Chem. Indian J. 12 (2013) 165-176.

4. C. S. Paim, F. Fuhr, M. Steppe, E. Schapoval and S. Eva, Gemifloxacin mesylate: UV spectrophotometric method for quantitative determination using experimental design for robustness, Quimica Nova. 35 (2012) 193-197; DOI: 10.1590/S0100-40422012000100033.

5. R. El-Bagary, N. F. Abo-Talib and M. B. N. Eldin, Validated stability indicating assay of gemifloxacin by different chromatographic and spectrophotometric methods of analysis, J. Chem. Pharm. Res. 3 (2011) 562-570.

6. S. S. Panda, B. V. V. Ravi Kumar, K. S. Rao, V. R. Kumar and D. Patanaik, Difference spectrophotometric determination of gemifloxacin mesylate in tablet formulation, Asian J. Biochem. Pharm. Res. 1 (2011) 442-447; DOI: 10.1002/bio.2347.

7. K. B. C. Sekhar, D. Madhuri and N. Devanna, Direct and derivative spectrophotometric determination of gemifloxacin mesylate via metal chelate, Acta Cienc. Indica, Ser. Chem. 36 (2010) 165171.

8. R. Rote Ambadas and S. P. Pingle, Validated UV-spectrophotometric methods for determination of gemifloxacin mesylate in pharmaceutical tablet dosage forms, E-J. Chem. 7 (Suppl. 1) (2010) S344-S348; DOI: 10.1155/2010/346847.

9. D. Madhuri, K. B. Chandrasekhar, N. Devanna and G. Somasekhar, Direct and derivative spectrophotometric determination of gemifloxacin mesylate in pure form and pharmaceutical preparations using $\pi$ acceptors, Int. J. Pharm. Sci. Res. 1 (2010) 222-230.

10. Z. Y. Al Shoaibi and A. A. Gouda, Spectrophotometric methods for the determination of gemifloxacin mesylate in pure form and pharmaceutical formulations, Anal. Chem: Indian J. 9 (2010) 129-136.

11. M. V. Krishna and D. G. Sankar, Utility of $\sigma$ and $\pi$-acceptors for the spectrophotometric determination of gemifloxacin mesylate in pharmaceutical formulations, E-J. Chem. 5 (2008) 493-498; DOI: $10.1155 / 2008 / 801545$.

12. S. E. K. Tekkeli and A. Önal, Spectrofluorimetric methods for the determination of gemifloxacin in tablets and spiked plasma samples, J. Fluoresc. 21 (2011) 1001-1007; DOI: 10.1007/s10895-010$0759-1$. 
B. A. Moussa et al.: Spectrofluorimetric determination of gemifloxacin mesylate and linezolid in pharmaceutical formulations: Application of quinone-based fluorophores and enhanced native fluorescence, Acta Pharm. 64 (2014) 15-28.

13. N. F. Youssef and L. I. Bebawy, Spectrofluorometric methods for the determination of gemifloxacin mesylate and cefamandole nafate in bulk powder and pharmaceutical preparations, Bull. Fac. Pharm. Cairo Univ. 44 (2006) 215-227.

14. A. A. Elbashir, B. A. Saad, S. M. Abdussalam, K. M. M. Al-Azzam and H. Y. Aboul-Enein, Validated stability indicating assay of gemifloxacin and lomefloxacin in tablet formulations by capillary electrophoresis, J. Liq. Chromatogr. Rel. Tech. 31 (2008) 1465-1477; DOI: 10.1080/10826070802039481.

15. A. R. Rote and S. P. Pingle, Reversed phase-HPLC and HPTLC methods for determination of gemifloxacin mesylate in human plasma, J. Chromatogr. B 877 (2009) 3719-3723; DOI: 10.1016/ j.jchromb.2009.08.013.

16. D. Nagavalli, G. Abirami and S. K. Kumar, Validated HPLC method for the simultaneous estimation of gemifloxacin mesylate and ambroxol hydrochloride in bulk and tablet dosage form, J. Pharm. Res. 4 (2011) 1701-1703.

17. J. H. Block and J. M. Beals, Wilson and Grisvold's Textbook of Organic Medicinal and Pharmaeutical Chemistry, 11 $1^{\text {th }}$ ed., Wolters Kluwer, Lippincott Williams \& Wilkins, New York 2004.

18. M. M. Annapurna, K. S. Kumar and M. V. V. S. G. Reddy, New derivative spectrophotometric methods for the determination of linezolid - an antibacterial drug, J. Chem. Pharm. Res. 4 (2012) 714-718.

19. S. A. Patel, P. U. Patel, N. J. Patel, M. M. Patel and U. V. Bangoriya, High performance thin layer chromatographic method for estimation of linezolid in tablets, Indian J. Pharm. Sci. 69 (2007) 571-574; DOI: 10.4103/0250-474X.36948.

20. S. Mohapatra, M. M. Annapurna, B. V. V. Ravi Kumar, M. Anwar, M. H. Warsi and S. Akhter, Validated stability indicating RP-HPLC method for the estimation of linezolid in a pharmaceutical dosage form, J. Liq. Chromatogr. Rel. Tech. 34 (2011) 2185-2195; DOI: 10.1080/10826076. 2011.585548 .

21. L. Vlase, D. Muntean, M. Cuciureanu, R. Cuciureanu and S. Gocan, High-throughput determination of linezolid in human plasma by liquid chromatography tandem mass spectrometry, $J$. Liq. Chromatogr. Rel. Tech. 34 (2011) 436-445; DOI: 10.1080/10826076.2011.555677.

22. D. Cattaneo, S. Baldelli, F. Conti, V. Cozzi and E. Clementi, Determination of linezolid in human plasma by high-performance liquid chromatography with ultraviolet detection, Ther. Drug Monit. 32 (2010) 520-524; DOI: 10.1097/FTD.0b013 e3181d5eeee.

23. N. M. El-Enany, A. Abdelal and F. Belal, Spectrofluorimetric determination of sertraline in dosage forms and human plasma through derivatization with 9-fluorenylmethyl chloroformate, Chem. Central J. 5 (2011) 56-63; DOI: 10.1186/1752-153X-5-56.

24. International Conference on Harmonization of Technical Requirements for Registration of Pharmaceuticals for Human Use, Q2 (R1): Validation of Analytical Procedures: Text and Methodology, ICH, Geneva 2005.

25. D. Liming, X. Qingqin and Y. Jianmei, Fluorescence spectroscopy determination of fluoroquinolones by charge-transfer reaction, J. Pharm. Biomed. Anal. 33 (2003) 693-698; DOI: 10.1016/507317085(03)00365-0.

26. M. F. Abdel Ghany, A. M. El Kosasy, M. F. Ayad and L. E. Abdel Fattah, Spectrophotometric and spectrofluorimetric determination of gentamicin and tobramycin using 1,4-benzoquinone, Bull. Fac. Pharm. Cairo Univ. 41 (2003) 69-88.

27. S. Sharif, I. U. Khan, T. A. Sheikh, Y. Sharif and M. Ashfaq, Validated stability-indicating HPLC method for analysis of gemifloxacin in tablet formulations, Acta Chromatogr. 41 (2011) 95-107; DOI: 10.1556/AChrom.23.2011.1.6.

28. J. Li and H. Wu, HPLC determination of linezolid plasma concentration, Chin. J. Mod. Appl. Pharm. 27 (2010) 353-355. 